\title{
Mídia, máquinas de imagens e práticas pedagógicas
}

\author{
Rosa Maria Bueno Fischer \\ Universidade Federal do Rio Grande do Sul, Faculdade de Educação e Programa de Pós-Graduação em Educação
}

\section{Três cenas}

Cena 1 - Meio urbano, cenário doméstico, atores de classe média. A menina de 12 anos mal chega em casa após um dia na escola (particular), e não consegue sequer trocar de roupa: liga o computador e, olhos em brilho, conecta-se ao MSN. Em segundos, estará em contato online com cinco, dez, vinte amigos, a maioria dos quais colegas com quem esteve há menos de uma hora, ao vivo. A mesma menina aguarda ansiosa o horário da novela das oito: desde seu quarto, escuta a música-tema de abertura do folhetim eletrônico, coloca-se temporariamente off-line no MSN, vai até a sala, senta-se ao sofá, janta sob protestos, está "vidrada" na tela. A seu lado, inseparável, o celular: é possível que algum torpedo chegue a qualquer momento, ou que alguém muito esperado ligue. O ouvido, de longe, continua atento aos sinais emitidos pelas entradas de possíveis novos amigos no MSN. Hiperconectada, isso não a impede de conversar com a mãe, responder a perguntas sobre novidades na escola, planejar o próximo fim de semana com o pai, a festa na noite de sexta-feira, o almoço com a madri- nha no domingo, ou combinar pelo telefone convencional a pesquisa escolar na Internet, na casa de uma amiga.

Cena 2 - Meio rural, próximo da capital gaúcha, ambiente externo, assentamento de agricultores do Movimento dos Trabalhadores Rurais Sem Terra (MST), atores jovens de camadas populares. O grupo de três adolescentes (duas meninas e um menino) acaba de sair da escola de ensino médio, uma escola pública estadual: todos portam seus celulares, não se cansam de consultar se há nova mensagem, se alguém ligou durante o tempo "silencioso" do aparelho, quando estavam em aula. Andam rápido, está quase na hora da novela adolescente Malhação. Como estará a personagem gordinha, o galã que todas desejam, a menina que vai fazer um teste para modelo? E a personagem de 16 anos que ficou grávida? O mundo deles está e ao mesmo tempo não está lá. Identificação e crítica mesclam-se. Os que têm computador em casa também se apressam, pois há possibilidade de saberem de novidades no Orkut: quantas pessoas terão acessado sua página? Não seria melhor mudar algum dado do profile? Quem sabe acrescentar uma foto ao 
álbum? E, claro, imediatamente clicar no scrapbook e ver as desejadas mensagens que lhe foram enviadas? Ou então entrar na página de um amigo e mandar a ele ou a ela aquilo que "só" pode ser dito ali, naquele privilegiado espaço digital? É preciso apressar-se. Mas há tempo também, muito tempo, para rir, chorar, comentar um desacerto com a professora, uma discussão com o pai ou a mãe, a pesquisa que precisam entregar depois de amanhã, ou então procurar a menina ou o menino desejados, nem que seja só com o olhar, na rua ao lado. Ideários do MST misturam-se sem distinção a sonhos de consumo e práticas com tecnologias digitais. O tempo é curto, o tempo é imenso, cabe tudo nele para esses jovens.

Cena 3 - Meio urbano, interior de uma sala de professores de escola municipal na periferia de Porto Alegre. Uma das professoras, recém-doutora, comenta o primeiro mês como docente. Será relativamente bem-remunerada, em comparação a professores da rede estadual. Mas não sabe se continuará na profissão. $\mathrm{O}$ que aprendeu na graduação, mestrado e doutorado parece não fazer sentido ali, naquela escola, com aqueles alunos. Algo ela sabe que não vai bem. Alguma coisa lhe traz profunda angústia. Os colegas ouvemna. E concordam: as crianças andam cada vez mais agitadas, algumas até muito violentas, agressivas com os companheiros de sala e com os professores. Elas não param de inserir durante as aulas comentários aprendidos na televisão, em geral irônicos, engraçados, que se misturam a tarefas didáticas, experiências de amizade, brigas na hora do recreio. Também os professores sabem da televisão, comentam a última artimanha da vilã maior da novela das oito, arriscam apostas sobre o final da trama folhetinesca e não vêem a hora de chegar em casa e jogar-se no sofá, "pra não pensar em nada". Não sem antes dar uma olhada na caixa de entrada de mensagens, no computador. Mesmo sem a presteza dos mais jovens, as professoras também "precisam" estar conectadas. E os professores homens, especialmente eles, não podem deixar de saber detalhes das imagens do último jogo da seleção brasileira: câmeras exclusivas da maior rede de televisão no país captaram o momento exato de uma con- tusão na coxa direita do maior jogador de futebol do mundo. Imperdível. E a professora angustiada e indecisa? Ela aproveita um excepcional tempo livre na escola para preparar o artigo científico em atraso, e busca na Internet uma referência bibliográfica: digita as palavras-chave e surgem na tela 167 mil sites sobre o assunto. Na página da biblioteca da universidade, são 86 títulos sobre o tema. É preciso refinar a busca, ela sabe. Mas como aceitar que a velocidade da informação seja diretamente proporcional a um excesso insuportável de dados disponíveis virtualmente? É demais, é demais para a jovem professora.

\section{"Novas tecnologias"? Ou transformações históricas nos modos de fazer e aprender?}

Para discutir o tema das relações entre mídia e trabalho pedagógico escolar, parto de cenas que poderiam ser multiplicadas ao infinito, com atores e situações bem diversos. No centro delas está a constatação de uma profunda alteração nos modos de existência contemporâneos, em que práticas cotidianas - também da escola, por certo - se transformam, particularmente no que se refere às nossas experiências com os saberes, às trocas com os outros, às formas de inscrever-nos no social, de escrever, de falar, de pensar o mundo e a nós mesmos.

Em vários estudos, nos últimos anos, ${ }^{1}$ tenho colocado em evidência algumas dessas alterações, que apontam para o que segue: a) o excesso e o acúmulo de informações, em relação ao tipo de experiência correspondente, de modo particular para crianças e jovens; b) a velocidade do acesso a fatos, imagens e dados, em relação a um tipo diferenciado de experiência com o tempo, a memória e a própria concepção aprendida de história; c) novos modos de viver a intimidade e a vida privada, em relação com a experiência política e as práticas sociais, nos diferentes espaços públicos; d) outros modos de compreender o que seriam as diferenças, de que tanto se fala,

\footnotetext{
${ }^{1}$ Ver, a propósito, Fischer (2005a, 2005b, 2005c, 2006).
} 
em relação às práticas do mercado, ávidas por novidades sempre "outras"; e) a centralidade do corpo e da sexualidade na cultura, em relação direta com a superexposição midiática de corpos infantis e juvenis; f) finalmente, a crescente miscigenação de linguagens de diferentes meios (cinema, televisão, fotografia, artes plásticas, pintura, computador, Internet), em relação às narrativas de agora - ficcionais, publicitárias, didáticas ou jornalísticas. Neste texto, elejo algumas delas para reforçar a urgência de incluir os materiais midiáticos, e suas relações com o social e o cultural, nos debates sobre didática e práticas de ensino.

Se observarmos bem, todos os tópicos anteriores apontam para uma expressão que temos chamado, no domínio das imagens, de "novas tecnologias". Como bem lembra o estudioso Philippe Dubois (2004), essa expressão remete invariavelmente, em nosso tempo, a instrumentos técnicos da informática e a um sem-número de recursos que permitem a fabricação de imagens. Porém, é preciso dizer que desde sempre a produção de objetos audiovisuais de qualquer tipo exigiu algum tipo de tecnologia: tratase da fabricação de algo, um artefato qualquer, que inevitavelmente exige instrumentos específicos, regras de criação, objetivos definidos e um tipo determinado de saber em jogo. Com os gregos clássicos, aprendemos que saber-fazer é algo que tem relação com a techné, a arte de fazer alguma coisa, independente de tratar-se de objetos "belos" (conhecidos como obras de arte) ou utilitários. Dubois cita o historiador Jean-Pierre Vernant, especialista em história clássica greco-romana, sugerindo que falar em techné reafirma historicamente o gesto humano de criar ferramentas e instrumentos aos quais recorremos para lutar contra algo que nos é superior, para dominar uma força - a natureza, as limitações de nosso corpo -, para ultrapassar limites (de tempo, espaço); talvez, no limite, se trate do desejo de enfrentar a grande força contra a qual desde sempre lutamos: a morte, a finitude humana. O exemplo mais citado e conhecido é o das pinturas rupestres, que há algum tempo sabemos existirem também em nosso país $^{2}$ - o que nos aproxima, paradoxalmente, disso que parece às vezes tão distante (a morte? o passado milenar?), num Brasil do qual sempre se afirma ser um país jovem.

Ora, não podemos ficar apenas nessa afirmação tão ampla, ou seja, que produzimos imagens com base em certa tecnologia para enfrentar a morte. É preciso ir além e, com apoio em Michel Foucault (2005), fazer a história de objetos técnicos, imagens, textos, sons, produtos audiovisuais, obras de arte, tomando-os por dentro de certa discursividade, estabelecendo as complexas relações entre um certo tempo, as verdades que nele se procura veicular e reafirmar, a materialidade da produção dessas verdades, as lutas em jogo e os modos de sujeição e subjetivação a elas correspondentes. Essa trama é que precisa ser descrita, quando nos debruçamos, por exemplo, sobre materiais midiáticos audiovisuais, em articulação com a vida de alunos e professores em suas práticas pedagógicas cotidianas.

Defendo a necessidade de um movimento incessante do pensamento no estudo das complexas relações que se podem fazer entre mídia e educação. Em primeiro lugar, não podemos perder de vista que, ao escolher a expressão "novas tecnologias", estamos assumindo uma verdade hegemônica de nosso tempo, pela qual se privilegia o novo pelo novo, promovendo apagamentos (como o citado anteriormente, sobre a techné, um saber-fazer inseparável do objeto a que se refere, seja ele de que ordem for - um filme, um livro, uma cadeira, um prato de culinária, uma peça de vestuário, uma mensagem enviada pelo Orkut, uma obra de Frida Kahlo). Outro apagamento comum nessa discussão, de caráter eminentemente conservador, é o que separa em mundos diferentes homens e máquinas, arte e tecnologia - como se isso fosse de algum modo possível. Como se a linguagem, a aprendizagem da fala, da leitura e da escrita, por exemplo, não fossem também elas tecnologias absolutamente

${ }^{2}$ Refiro-me especialmente aos sítios arqueológicos do estado do Piauí, que nos conduzem às evidências de ocupação humana nessa região há mais de 10 mil anos. 
sofisticadas - como nos alerta Arlindo Machado (1996), no livro Máquina e imaginário.

É necessário ainda abandonar afirmações amplas demais, quase assépticas, que ignoram tempos e lugares específicos, grupos sociais, gente de carne e osso, enfim, quando se discutem as tais "novas tecnologias". Assim, ao estabelecer um debate entre mídias, tecnologias e educação, creio ser fundamental delimitar de que grupos estamos falando, de que época e de que região deste planeta estamos tratando. Em outras palavras, entendo que se torna cada vez mais urgente discutir como, historicamente, em nosso país, poderia ser pensado o embate entre tecnologias midiáticas e práticas pedagógicas. ${ }^{3}$ Vejamos o caso do Orkut. Criado em 2004, o sistema Orkut de comunidades virtuais em apenas seis meses de existência já havia reunido mais de dois milhões de usuários, $30 \%$ deles brasileiros e $30 \%$ norte-americanos. Segundo dados do próprio site do Orkut, citados pelos pesquisadores José Eisenberg e Diogo Lyra (2006), em setembro de 2005 o Brasil aparecia como o usuário maior ( $75 \%$ dos membros eram brasileiros, a maioria dos quais com menos de 30 anos de idade). Permitir que cada usuário tenha a sua própria página e possa participar das mais diversas comunidades parece ser

${ }^{3}$ Em um encontro de pesquisadores da região do Mercado Comum do Sul (Mercosul), em Buenos Aires, em junho de 2006, na II Reunião da Sociedade Brasileira para o Progresso da Ciência e da Associación Argentina para el Progreso de las Ciências, fez-se uma comparação entre Argentina e Brasil, sobre o que, nesses países, marcaria fundamentalmente certa unidade nacional. $\mathrm{Na}$ mesa de que participei, intitulada "La escuela en la encrucijada cultural. El impacto del cambio cultural de la sociedad mediática y de la sociedad de la información sobre los procesos pedagógicos", um dos tópicos principais do debate foi que a televisão, no Brasil, seria o grande dispositivo de produção de certa identidade nacional; no caso da Argentina, apesar da força da televisão, ainda hoje o que promoveria uma identidade e participação nacional seria, primordialmente, a escola, segundo a coordenadora da mesa, Inês Dussel (professora da Facultad Latinoamericana de Ciencias Sociales - FLACSO, Argentina). o atrativo principal desse sistema. Mas ainda é prematuro chegar a conclusões seguras sobre o que estaria unindo brasileiros e norte-americanos nessa preferência, semelhante à paixão dos dois públicos também pelas séries televisivas, telenovelas, soap operas, sem falar em toda a sorte de reality shows. O estudioso inglês Roger Silverstone (2002), em Por que estudar a mídia?, mostra como é impossível pensar as relações entre mídia e educação sem pensar em lutas de poder, em estratégias de controle globalizadas, em batalhas pelo controle das grandes redes de comunicação e, ao mesmo tempo, em lutas de grupos e indivíduos para terem acesso e participação quanto à informação e ao direito de voz e de expressão.

O importante aqui é sublinhar que todas essas mídias, do rádio à internet e à televisão, têm um caráter de onipresença, tornam-se cada vez mais essenciais em nossas experiências contemporâneas, e assumem características de produção, veiculação, consumo e usos específicos em cada lugar do mundo. Interessam-nos, então, os materiais e os sujeitos produtores e usuários dessas mídias, aqui no Brasil; mais ainda, interessam-nos os modos de apreender os fatos da cultura, pelos mais jovens, modos que assumem particularidades quando vistos a partir do olhar de educadores, no cotidiano das vivências escolares.

\section{Juventude e memória cultural: um caso a pensar}

Na pesquisa "Alteridade e cultura midiática: memórias de juventude", ${ }^{4}$ para citar um exemplo de como se poderia visualizar o debate aqui proposto, busco marcas de produtos dos meios de comunicação e da publicidade na história de jovens estudantes de 15 a 25 anos, sobre sua história com a mídia impressa e audiovisual, com a cultura do espetáculo, do consumo e das celebridades narcísicas - temáticas preferi-

${ }^{4}$ Pesquisa realizada com apoio do Conselho Nacional de Desenvolvimento Científico e Tecnológico (CNPq) (bolsa de produtividade em pesquisa e de iniciação científica), iniciada em 2005. 
das, ídolos, referências, lembranças afetivas, marcas inscritas em seus corpos. A hipótese é que as narrativas midiáticas se constroem e se endereçam a diferentes públicos, constituindo a juventude como um "outro" desejado e desejável, a ser permanentemente capturado a partir de um imaginário que busca recobrir espaços em branco, passíveis no entanto de outras e inesperadas simbolizações (cf. Fischer, 2005b). É interessante ver que, especialmente nos produtos da publicidade, sem falar em um conjunto quase interminável de seriados, em geral de origem norte-americana, encontramos essa recorrência: jovens que se tornam o ponto de chegada e de desejo para os mais velhos e para crianças e adolescentes, mas que se vêem às voltas com um "passado" muito recente, cujas marcas são dadas por produtos midiáticos diversos, jamais desvinculados de práticas consumistas, mas que não se reduzem a isso, já que também são marcas plenas de memória afetiva. ${ }^{5}$

Usando esse exemplo, procuro explicitar a preocupação com um recorte específico de estudo - no caso, as relações entre memória, mídia e juventude no Brasil -, articulando conceitos de autores como Slavoj Zizek (2003), Bergson (1990) e Foucault (2005), e a importância de exercitarmos formas imaginativas diversas de cercar esse grande tema dos cruzamentos entre mídias e práticas pedagógicas. Jovens do ensino médio e dos primeiros semestres do ensino superior, no caso citado, passam a ser o foco de atenção, junto com a pergunta sobre como se alteram em nosso tempo as formas de esses meninos e essas meninas se relacionarem com o tempo e a história, com

${ }^{5}$ Um comercial da Chevrolet, veiculado em 2007, parece exemplificar com perfeição o que temos investigado na pesquisa: nele, em apenas 30 segundos, um jovem de seus 20 anos tem sua vida resumida a uma seqüência quase lírica de imagens que reúnem figuras como o Papai Noel, o Saci, Chucky (do filme $O$ brinquedo assassino), Zorro, "coelhinhas” da Playboy, o boneco Fofão, familiares em festa de casamento, personagens circenses, Scooby Doo, soldadinhos de chumbo. O texto é este: "Sua vida trouxe você até aqui. Novo Prisma, seu primeiro carro". as memórias que têm de si mesmos; ainda, a pergunta sobre como os meios de comunicação constroem uma suposta alteridade juvenil, como nomeiam os adolescentes e jovens, como os cercam de propostas de normalização, e assim por diante.

Dito isso - que, ao estudar o que tenho chamado de "dispositivo pedagógico da mídia", sempre estamos de alguma forma tratando de objetos, tecnologias e saberes históricos, imersos em relações de poder, produtores de subjetividades -, passo a comentar brevemente transformações culturais e sociais referidas anteriormente, e que apontam para necessários rearranjos em nossas práticas curriculares e didáticas, especialmente no ensino básico.

\section{Informações em excesso, acesso e velocidade: novas experiências com o tempo e a memória}

Em Matéria e memória, Bergson (1990, p. 197) escreve que

[...] nosso presente não deve se definir como o que é mais intenso: ele é o que age sobre nós e o que nos faz agir, ele é sensorial e é motor; nosso presente é antes de tudo o estado do nosso corpo. Nosso passado, ao contrário, é o que não age mais, mas poderia agir, o que agirá ao inserir-se numa sensação presente da qual tomará emprestada a vitalidade.

O importante é esse movimento, do presente ao passado e do passado ao presente; Bergson diz que não se trata, na memória, de uma regressão ao passado, mas de um "progresso do passado ao presente" (idem, p. 196). Trata-se de um estado de "virtualidade" do passado, algo que vai sendo conduzido "através de uma série de planos de consciência diferentes, até o termo em que ele se materializa numa percepção atual, isto é, até o ponto em que ele se torna um estado presente e atuante, ou seja, enfim, até esse plano extremo de nossa consciência em que se desenha nosso corpo. Nesse estado virtual consiste a lembrança pura" (idem, p. 196-197).

Ora, nosso presente, hoje, é feito fortemente de narrativas a que temos acesso por nossas relações com 
a internet e a televisão; é esse presente, com todas as suas metáforas, ícones, modos de simbolizar nossas experiências mais diversas, que opera em nós, acionando memórias, construindo e reconstruindo um jeito de entender o que seria nossa história, pessoal e social. A televisão, já se disse tantas vezes, é uma grande contadora de histórias; ela faz-nos retrospectivas, a cada final de ano, a cada final de década e até de século, como vivemos na entrada do ano 2000. Ela vai indicando que fatos, que imagens, que sentimentos precisam ser adicionados aos nossos arquivos individuais e coletivos. Um século pode ser-nos contado por imagens e sons em 60 minutos, em menos de duas horas. O cinema, igualmente: como não se comover com a beleza das imagens garimpadas pelo diretor Marcelo Masagão no premiado documentáriomemória do século XX, Nós que aqui estamos por vós esperamos, de 1998 ?

Silverstone (2002) insiste, nesse sentido, que estudar a mídia é investigar não só nossas relações com o amor à narrativa, mas também os modos de a cultura midiática construir passados públicos, "assim como um passado para o público" (p. 237). Vidas vividas e vidas narradas (no caso, narradas no espaço midiático) parecem mesmo estar em íntima relação. Real e ficção confundem-se incessantemente nos produtos da mídia. Os códigos culturais, visíveis e vividos no interior dos diferentes espaços sociais - inclusive e especialmente nos meios de comunicação - constituem, pautam, normalizam e normatizam não só a própria criação, a elaboração das narrativas, como ainda o modo pelo qual elas são lidas, percebidas, recebidas pelas pessoas. Vale lembrar aqui que em todas as pesquisas de recepção, com crianças e jovens de diferentes camadas sociais, a grande preferência quanto a programas de televisão é a de narrativas ficcionais: filmes, telenovelas, seriados, minisséries, desenhos animados. Não importa o endereçamento explícito, se os programas são destinados ou não a públicos infantis e juvenis. O que conta é o desejo de ver e ouvir histórias. É como se todos buscassem naquelas narrativas um pouco da sua própria história, da história de seus afetos e medos, de seus desejos e sonhos.
Em acordo com o que escreve Bergson sobre a memória, Silverstone diz que memória é trabalho, e que esse trabalho hoje não existe sem a concorrência do que aprendemos e vemos diariamente nos telejornais, filmes, novelas, talk shows, reality shows, quando participamos de jogos eletrônicos on-line, quando criamos e mantemos páginas e comunidades virtuais inventadas por nós mesmos. Haveria uma mediação fundamental da mídia na construção e produção das nossas memórias: para o educador, abre-se um leque de novas indagações sobre como tratar o histórico nas diferentes áreas do conhecimento - matemático, geográfico, literário, lingüístico etc. Que modos de contar e de ouvir histórias as crianças e jovens de nosso tempo experimentam? Como isso aparece nas facilidades ou dificuldades vividas em sala de aula? Que impaciências ou que desejos de saber sobre a história de seu país, de seu grupo social, as crianças mostram? Como essas manifestações aparecem cotidianamente no trabalho pedagógico escolar?

A análise de algumas narrativas da mídia - por exemplo, aquelas referentes à vida de um jogador de futebol ou de uma jovem desportista de ginástica olímpica - pode ajudar a compreender o que digo. Revistas, jornais, reportagens de televisão, com freqüência transformam meteoricamente esses quase meninos literalmente em heróis, seja por um gol salvador, seja por uma performance inusitada da ginasta em salto sobre o cavalo de madeira. A palavra usada é essa, sempre, à exaustão: herói. Misturam-se nessa imagem: a memória que guardamos de um Ulisses da epopéia grega, a ação de um líder de movimento social negro, feminista ou homossexual de nosso tempo, enfrentando governos ou grupos conservadores; ou a lembrança de bombeiros a salvar vidas em catástrofes ou acidentes. Tudo se mescla, tudo se confunde. Com uma velocidade e uma instantaneidade inimagináveis em outros tempos, não só temos acesso a informações e imagens, mas ouvimos e lemos histórias transformadas em grandes feitos, marcados por uma adjetivação de excelência, onde tudo é "super", "extra", "mega". O jovem jogador de futebol vindo da zona norte carioca torna-se um Ulisses brasileiro; a adolescente des- 
coberta no meio rural gaúcho transmuda-se em modelo de grife e é batizada de deusa.

Ora, esses exemplos estão aqui tão-somente para problematizar imagens e narrativas midiáticas, de modo que se possa pensá-las como objetos de estudo no meio escolar. ${ }^{6}$ Neste caso, escolheu-se um dos aspectos da produção, veiculação e consumo de imagens audiovisuais, a saber: a velocidade, a supressão dos períodos mais longos, a ausência de pausas, a dificuldade com os períodos mais longos (confundidos com velhice, obsolescência, morosidade) e o correspondente fascínio pelos superlativos. Reafirmo: tais elementos fazem parte dos discursos de nossa época e são aprendidos pelas crianças desde que nascem, habitam suas vidas, participam da construção de suas subjetividades, transformam seus modos de aprender e de existir.

\section{Sobre linguagem audiovisual e representação: novos (?) problemas para a educação}

Cada vez que uma nova tecnologia de comunicação surge, cada vez que uma nova máquina de imagens se impõe, ela chega como moda e novidade e parece colocar na sombra "máquinas" anteriores: em sequiência, é o que aconteceu com o surgimento da fotografia, do cinema, da televisão, do vídeo, da imagem digital e da informática. Dubois (2004) vai direto ao ponto: na verdade, a cada nova tecnologia de produção de imagens, mais uma vez somos colocados diante de antigas questões sobre o problema da representação e da figuração. Insistir que estamos diante de algo "novo" seria apostar na ideologia do progresso contínuo. Talvez o melhor caminho fosse pensar, como já fizeram muitos pensadores da filosofia e da sociologia da comunicação, que cada nova tecnologia transforma, "ecologicamente", os modos de conhecer, como escreveu Pierre Lévy (1995), em As tecnologias da inteligência, ao apresentar-nos ao produtivo conceito de "ecologia cognitiva".

${ }^{6}$ Ver a propósito o artigo "Problematizações sobre o exercício de ver: mídia e pesquisa em educação" (Fischer, 2002).
Em outras palavras, instrumentos como a máquina fotográfica, a câmera de vídeo, a filmadora, organizam nosso olhar, apontam caminhos muito concretos de como podemos e devemos "apreender o real", como podemos e devemos "enquadrar" rostos, cenas, corpos, sentimentos até. Mas se considerarmos não apenas o sujeito que usa a máquina, capta e fixa as imagens, mas aquele que as recebe, o espectador do cinema e da televisão, por exemplo, temos que se abre aí um campo riquíssimo para estudiosos de diversas áreas do saber, sobretudo para educadores ocupados com as transformações nos modos de aprender: o fato é que à dimensão tecnológica se associa sempre uma dimensão simbólica fundamental.

Ou seja, estudar as imagens, os processos de produção de materiais audiovisuais, as diferentes formas de recepção e uso das informações, narrativas e interpelações de programas de televisão, filmes, vídeos, jogos eletrônicos, corresponderia, ao meu ver, a práticas eminentemente pedagógicas e indispensáveis ao professor que atua nestes tempos. Isso porque há todo um trabalho de simbolização, no lugar daquele que imagina, planeja, produz e veicula filmes, novelas, telejornais, vídeos, assim como há um trabalho permanente de simbolização, no lugar daquele que se apropria do que vê e ouve a partir das diferentes mídias.

O pensamento crítico sobre essa matéria não estaria, penso, em simplesmente acompanhar um pretenso progresso evolutivo da produção e do uso de imagens, com tecnologias cada vez mais sofisticadas, e os respectivos problemas com uma possível regressão do "artístico" e do "humano" (Dubois, 2004, p. 42-43), como muitas vezes até hoje nos manifestamos, ao fazer a crítica aos meios de comunicação e às tais "novas tecnologias". Diferente disso, trata-se de apanhar cada produto midiático em sua concretude histórica, comunicacional, mercadológica, política, e também como material que é produzido e veiculado segundo um determinado aparato técnico que, por si mesmo, também produz efeitos em nós. Uma pintura tem uma "realidade" física palpável, diferente, por exemplo, da cópia fotográfica em papel. Um filme é 
projetado na tela grande do cinema, na sala escura e (em princípio) silenciosa. Já um produto televisivo chega-nos como luz projetada sobre nosso corpo, em meio a um cotidiano doméstico, informal e disperso; a televisão traz-nos o mundo, e o mundo parece que é propriedade nossa, em tempo real: sujeito e objeto desaparecem, escreve Dubois, "não há mais Comunhão, só nos resta a Comunicação" (idem, p. 47). Na seqüência, com as imagens digitais no computador e o acesso à Internet, chegamos a uma maquinaria que pode ela mesma produzir o seu "real" - isto é, produzir a partir daquela tecnologia a imagem que se desejar.

Estamos tratando aqui de um problema conceitual da maior importância: crianças hoje se alfabetizam numa época em que as próprias tecnologias de informação e comunicação nos forçam a pensar de outra forma o que muitos filósofos e artistas já discutiram há pelo menos 30 ou 40 anos: a idéia de representação perde seu sentido, já não se sustenta. Um autor como Foucault, por exemplo, discute e questiona em suas obras as filosofias da representação, a busca daquilo que foi dito pela primeira vez em algum dado lugar e tempo, a procura interminável da origem, da semelhança, da imitação, enfim, da fidelidade, da coincidência entre o dito e o que ele representa ou pode vir a representar, a partir de nossas interpretações. A literatura, o cinema, a pintura, todas as artes e, mais recentemente, a linguagem eletrônica e informatizada, todas essas práticas perturbam o grande modelo da representação, tão caro inclusive às práticas pedagógicas, ainda hoje. Ora, não há isomorfismo entre o visto e o falado, entre a palavra e a coisa. Criar, escrever, pintar também são dessa ordem, têm a ver com esse espaço que não se deixa apanhar por completo, que é luta, que é fuga do instituído, que jamais se torna forma fixa.

Paradoxal é que, ao analisar práticas e materiais no âmbito das mais recentes tecnologias de informação e comunicação, e de produção de imagens digitais, muitas vezes observamos que o esforço está justamente em procurar reproduzir, no computador, a figura humana ou a paisagem mais próxima da "realidade", mais próxima de uma "imagem tradicional".
Veja-se como a Rede Globo de Televisão insere, num de seus programas de maior audiência, o Fantástico, uma apresentadora totalmente virtual, curiosamente chamada "Eva Byte". Essa busca de mais "realidade" pelo virtual convive com as experiências de pura simulação, a partir de máquinas que funcionam não mais como próteses de nossos olhos e ouvidos (no caso, os equipamentos de vídeo e de som), mas como próteses de nossas mãos. O controle remoto, a magia do mouse, as telas táteis, os capacetes de visão - tudo o que Philippe Dubois chama de "dispositivos de frustração" -, contraditoriamente, buscam oferecer ao usuário um modo de "tocar a realidade":

Hipertrofia do ver e do tocar, por parte de um sistema de representação tecnológica que carece cruelmente de ambos, por ter dado as costas ao Real. As telas se acumularam a tal ponto que apagaram o mundo. Elas nos tornaram cegos pensando que poderiam nos fazer ver tudo. Elas nos tornaram insensíveis pensando que poderiam nos fazer sentir tudo. (Dubois, 2004, p. 66-67)

Mas são essas mesmas tecnologias, essas mesmas "máquinas de imagens" que nos fascinam, que interpelam com seus produtos as crianças, jovens, adultos de todas as idades. Estudá-las, na complexidade de todas as relações em jogo, de produção e criação, de veiculação e consumo, de fruição e apropriação, significa pensar o tempo presente, dizer a nós mesmos como nos tornamos o que chegamos a ser hoje, sujeitos de determinadas verdades e de certos modos de existência "tecnológica" - vividos como encantamento e fascínio, e ao mesmo tempo como frustração e sensação de impotência.

\section{Ampliação de repertórios: um modo de produzir pensamento}

Para concluir, gostaria de imaginar a possibilidade de operar com os materiais midiáticos, nos espaços escolares, para além dos conhecidos exercícios de crítica reducionista aos meios de comunicação, que parece restringir-se majoritariamente a "desvelar" as 
intencionalidades das emissoras de televisão, dos produtores e diretores de cinema, identificando ideologias, manipulações e distorções da "realidade". Ao meu ver, esse parece ser o caminho mais fácil, o já trilhado, aquele em que não arriscamos descrever a complexidade dos processos comunicacionais. Apostar que há um emaranhado rico de práticas, envolvendo toda uma tecnologia de produção de imagens, modos diferenciados de recepção e apropriação de narrativas audiovisuais, é apostar na análise das mídias como elementos fundamentais da cultura contemporânea. Significa também arriscar a pensar que há um sem-número de materiais audiovisuais, do cinema, do vídeo e da televisão, em que as escolhas éticas e estéticas dos criadores se pautam pelas incertezas da linguagem, pelo não fechamento das interpretações, pelas pequenas cintilações de uma obra aberta, disponível a um criativo gesto educacional.

Talvez um dos trabalhos pedagógicos mais revolucionários seja o que se refere a uma ampliação do repertório de professores, crianças e adolescentes, em matéria de cinema, televisão, literatura, teatro, artes plásticas e música. Pesquisar e montar videotecas, alugar vídeos e DVDs com materiais selecionados, diferenciados daquilo que se vê cotidianamente e que circula na grande mídia, parece-me fundamental para educar olhos e ouvidos, educar a alma, de modo que o pensamento crítico se forme aí, tanto na escuta do que os mais jovens vêem e produzem a partir das tais "novas tecnologias", como na oferta de algo mais, de alguma imagem inesperada que um programa de televisão mais elaborado pode colocar à nossa disposição. A ampliação do repertório pode configurar-se inclusive como o exercício de outras formas de recepção e apropriação dos próprios materiais cotidianos, presentes na mídia e fartamente consumidos por alunos e professores.

Nesse sentido, de educação audiovisual, imagino que o cinema tenha muito a acrescentar ao trabalho pedagógico escolar. Quando o filósofo Alain Badiou fala sobre a pureza e a impureza das imagens cinematográficas, mostra-nos que o cinema é uma arte suja, que parte da desordem, se faz em meio a proble- mas de dinheiro, de lucro, da lógica do mercado, que exige cenários, paisagens, gente, espaços diferentes, corpos, atores, equipamentos, roteiristas, toda uma maquinaria coletiva (como acontece, aliás, com a televisão, as revistas, os jornais, cada mídia a seu modo). Porém, há diretores que, de dentro dessa desordem e impureza, tentam escapar ao já dito, ao já instituído, tentam chegar a uma simplicidade generosa e instigadora do pensamento, para aqueles a quem se endereçam. Como escreve Badiou (2004), de todo o ruído contemporâneo (de banalidades várias, de imagens estúpidas de carros em perseguição, por exemplo, de grandes explosões, de pornografia gratuita, imagens inúteis, gritarias, cores e diálogos em excesso), alguns diretores conseguem inventar e produzir um silêncio criativo, uma seqüência amorosa delicada e erótica, a interpretação digna de um ator, a manifestação de uma experiência humana singular, a apresentação de um outro diferente de nós, que nos confronta e nos convida a saber dele. Isso não deixará de tocar espectadores atentos, pessoas que, na escola, por exemplo, um dia aprenderam a distinguir imagens, a pensar com imagens, a amar narrativas diferentes das costumeiras e repetidas.

Investir na ampliação de repertório como proposta educacional tem esse sentido: ampliar as possibilidades de estabelecer relações, de ligar um trecho de Chico Buarque e uma cena de Pedro Almodóvar, por exemplo; ou versos de Cecília Meirelles a uma cena de desenho animado fora da grande mídia; perguntar-se sobre o nome da apresentadora virtual Eva Byte e sobre a tecnologia digital que não abre mão da "realidade"; realizar uma pesquisa de audiência, feita por alunos adolescentes, com crianças da mesma escola que eles freqüentam, sobre o que vêem na televisão todos os dias; produzir um novo roteiro para os mesmos personagens de uma telenovela, quem sabe apoiando-se na leitura de um conto de Guimarães Rosa ou de Machado de Assis. Por que não? As possibilidades são infinitas. E podem propiciar que nós, professores, alunos e alunas, ousemos criar um saberfazer, como ferramentas diferenciadas para pensar de outro modo o presente que vivemos. 


\section{Referências bibliográficas}

BADIOU, Alain. El cine como experimentación filosófica. In: YOEL, Gerardo (Comp.). Pensar el cine 1. Imagen, ética y filosofia. Buenos Aires: Manantial, 2004. p. 23-81.

BERGSON, Henri. Matéria e memória. Trad. Paulo Neves. São Paulo: Martins Fontes, 1990.

DUBOIS, Philippe. Cinema, vídeo, Godard. Trad. Mateus Araújo Silva. São Paulo: Cosac Naify, 2004.

EISENBERG, José; LYRA, Diogo. A invasão brasileira do Orkut. Ciência Hoje, v. 38, n. 226, p. 30-35, 2006.

FISCHER, Rosa Maria Bueno. Televisão \& educação: fruir e pensar a TV. 3. ed. Belo Horizonte: Autêntica, 2006.

. Diante do real midiático: contribuições de Zizek, Arendt e Sontag aos estudos de recepção. In: CAPPARELLI, Sérgio; SODRÉ, Muniz; SQUIRRA, Sebastião (Orgs.). A comunicação revisitada. Porto Alegre: Sulina, 2005a.

. Mídia e educação: em cena, modos de existência jovem. Educar em Revista, UFPR, n. 26, p. 17-38, 2005 b.

. Mídia e juventude: experiências do público e do privado na cultura. Cadernos CEDES, v. 25, n. 65, p. 43-58, 2005 c.

. Problematizações sobre o exercício de ver: mídia e pesquisa em educação. Revista Brasileira de Educação, Rio de Janeiro: ANPEd, n. 20, p. 83-94, 2002.

FOUCAULT, Michel. A arqueologia do saber. 7. ed. Trad. Luiz Felipe Baeta Neves. Rio de Janeiro: Forense Universitária, 2005. LÉVY, Pierre. As tecnologias da inteligência. O futuro do pensamento na era da informática. Trad. Carlos Irineu da Costa. Rio de Janeiro: Ed. 34, 1995.
MACHADO, Arlindo. Máquina e imaginário. 2. ed. São Paulo: EDUSP, 1996.

SILVERSTONE, Roger. Por que estudar a mídia? Trad. Milton Camargo Mote. São Paulo: Loyola, 2002.

ZIZEK, Slavoj. Bem-vindo ao deserto do real. Trad. Paulo Cezar Castanheira. São Paulo: Boitempo, 2003.

ROSA MARIA BUENO FISCHER, doutora em Educação pela Universidade Federal do Rio Grande do Sul (UFRGS), é professora da mesma instituição, na qual coordena o Núcleo de Estudos sobre Mídia, Educação e Subjetividade (NEMES). É pesquisadora do Conselho Nacional de Desenvolvimento Científico e Tecnológico (CNPq) desde 1998 e editora da revista Educação \& Realidade. Foi coordenadora do grupo de trabalho (GT) Educação e Comunicação da ANPEd, em 2005 e 2006. É membro do Comitê Científico da ANPEd (2007). Publicações recentes: Educação \& televisão: fruir e pensar a TV (3. ed., Belo Horizonte: Autêntica, 2006); Infância, mídia e experiência (In: GURSKI, R.; DALPIAZ, S.; VERDI, M. S. (Orgs.). Cenas da vida atual. A família, a escola e a clínica. Ijuí: Ed. UNIJUÍ, 2006); Escrita acadêmica: arte de assinar o que se lê (In: COSTA, Marisa Vorraber; BUJES, Maria Isabel Edelweiss (Orgs.). Caminhos investigativos III: riscos e possibilidades de pesquisar nas fronteiras. Rio de Janeiro: DP\&A, 2005). Pesquisa em andamento: "Alteridade e cultura midiática: memórias de juventude", com financiamento do CNPq. E-mail: rosabfischer@terra.com.br

Recebido em outubro de 2006 Aprovado em fevereiro de 2007 